\title{
Clinical utility of asthma biomarkers: from bench to bedside
}

\author{
Susanne JH Vijverberg ${ }^{1,2, *}$ \\ Bart Hilvering $2, *$ \\ Jan AM Raaijmakers' \\ Jan-Willem J Lammers ${ }^{2}$ \\ Anke-Hilse Maitland-van \\ der Zee ${ }^{1, *}$ \\ Leo Koenderman ${ }^{2, *}$
}

'Division of Pharmacoepidemiology and Clinical Pharmacology, Utrecht

Institute for Pharmaceutical

Sciences, Faculty of Science, Utrecht

University, Utrecht, The Netherlands;

${ }^{2}$ Department of Respiratory Medicine,

University Medical Centre Utrecht,

Utrecht, The Netherlands

*These authors contributed equally to this work

Correspondence: Anke-Hilse Maitlandvan der Zee

Division of Pharmacoepidemiology and Clinical Pharmacology,

Utrecht University, Faculty of Science,

PO Box 80082, 3508 TB Utrecht,

The Netherlands

Tel +31622736715

Fax +31302539166

Email a.h.maitland@uu.nl
This article was published in the following Dove Press journal:

Biologics:Targets and Therapy

28 August 2013

Number of times this article has been viewed

\begin{abstract}
Asthma is a chronic disease characterized by airway inflammation, bronchial hyperresponsiveness, and recurrent episodes of reversible airway obstruction. The disease is very heterogeneous in onset, course, and response to treatment, and seems to encompass a broad collection of heterogeneous disease subtypes with different underlying pathophysiological mechanisms. There is a strong need for easily interpreted clinical biomarkers to assess the nature and severity of the disease. Currently available biomarkers for clinical practice - for example markers in bronchial lavage, bronchial biopsies, sputum, or fraction of exhaled nitric oxide (FeNO) - are limited due to invasiveness or lack of specificity. The assessment of markers in peripheral blood might be a good alternative to study airway inflammation more specifically, compared to FeNO, and in a less invasive manner, compared to bronchoalveolar lavage, biopsies, or sputum induction. In addition, promising novel biomarkers are discovered in the field of breath metabolomics (eg, volatile organic compounds) and (pharmaco)genomics. Biomarker research in asthma is increasingly shifting from the assessment of the value of single biomarkers to multidimensional approaches in which the clinical value of a combination of various markers is studied. This could eventually lead to the development of a clinically applicable algorithm composed of various markers and clinical features to phenotype asthma and improve diagnosis and asthma management.
\end{abstract}

Keywords: asthma, airway inflammation, biological markers, pharmacogenomics, metabolomics

\section{Introduction to the pathophysiology of asthma}

Asthma affects over 300 million individuals worldwide, ${ }^{1}$ making it one of the most prevalent common chronic diseases. Although the respiratory disease is rarely fatal, the economic burden is extensive due to direct and indirect medical expenses, including prescription drug costs, health care costs, and productivity losses. ${ }^{2}$

The disease is characterized by airway inflammation, bronchial hyperresponsiveness, and recurrent episodes of reversible airway obstruction. Asthma can be classified as "atopic" or "nonatopic" based on the presence (atopic) or absence (nonatopic) of specific immunoglobulin ( $\mathrm{Ig}) \mathrm{E}$ antibodies to common environmental allergens. Atopic asthma is the most common form of asthma. In allergen-sensitized patients with atopic asthma, re-exposure to an aeroallergen will lead to an IgE-mediated inflammatory cascade in the airways. Airway resident cells (ie, macrophages and mast cells), newly mobilized immune cells (ie, eosinophils and neutrophils), and epithelial cells play an important role in this inflammatory cascade. ${ }^{3}$ In allergic inflammation, there seems to be a disturbed balance in T helper (Th)1-type and Th2-type cytokines - with dominance 
towards Th2 cytokines. ${ }^{4}$ Th2 cells produce cytokines such as interleukin (IL)-4 and IL-13, which induce a class-switch in B-cells to the production of IgE. Th2 cells also produce IL-5, which recruits eosinophils to the lung, and IL-9, which stimulates mast cell proliferation. Upon activation, mast cells start to produce histamine, cysteinyl-leukotrienes, and prostaglandin D2, which in its turn will lead to the additional recruitment of eosinophils, Th2 cells, and basophils to the tissue. ${ }^{5}$

Parallel to the allergic asthma model with airway epithelial cells and the adaptive immune response as important pillars, an additional nonallergic asthma paradigm has been proposed. In the nonallergic asthma model, the innate immune system responds to constantly invading respiratory viruses and bacteria. This systemic innate response is driven by sentinel cells such as macrophages, dendritic cells, granulocytes, and innate lymphoid cells. A recent review by Holtzman provides a comprehensive overview of both the allergic and nonallergic immune response in asthma. ${ }^{6}$

A prolonged presence of activated inflammatory cells in the airways leads to chronic inflammation and induces tissue alterations in composition, content, and organization of the airways ("airway remodeling"). Important cytokines released by epithelial cells and associated with remodeling are IL-25, thymic stromal lymphopoietin, and IL-33. The remodeling response is characterized by subepithelial basement membrane thickening, epithelial cell disruption, neoangiogenesis, goblet cell metaplasia, enlarged submucosal glands, and airway smooth muscle hyperplasia. ${ }^{7}$ This airway remodeling is regarded as a continuous process, while the number of inflammatory cells infiltrated in the respiratory tract can vary over time. This latter process is evoked by stimuli such as allergens, climate, or respiratory tract infections. However, the observation of airway remodeling in young asthma patients suggests that the process may even precede airway inflammation. ${ }^{8}$

\section{Asthma biomarkers for diagnosis, phenotyping, and treatment efficacy}

Asthma diagnosis and management is generally based on reported asthma symptoms, often combined with lung function tests to assess reversible airway obstruction and airway hyperresponsiveness. However, symptoms and lung function measurements may not reflect underlying airway inflammation. Bronchoscopy with biopsies and bronchoalveolar lavage (BAL) are considered the gold standard to assess airway inflammation, but are too invasive for general application in clinical practice. ${ }^{9}$ In addition, asthma seems to encompass a broad collection of heterogeneous disease subtypes with different underlying pathophysiological mechanisms. ${ }^{10}$ There is a need for asthma biomarkers to identify clinical relevant asthma phenotypes, optimize diagnosis, and guide treatment. In this paper, we will provide an overview of asthma biomarkers already available for clinical practice and promising biomarkers currently under development (Figure 1). In addition, we will address the promises and barriers of the implementation of asthma biomarkers into clinical practice.

\section{Clinically available biomarkers Sputum induction, bronchoscopy/biopsy, and bronchoalveolar lavage}

Tissue-specific diagnostic methods such as bronchoalveolar lavage, bronchoscopy, or bronchial biopsy, are used to measure airway inflammation and remodeling, and provide reliable and detailed clinical information of asthmatic patients. Airway remodeling has been observed in bronchial biopsies of both adults and children with asthma. ${ }^{11}$ BAL fluid of asthmatic patients shows elevated levels of Th2 cytokines compared to healthy individuals. ${ }^{12}$ In difficult-to-treat asthma in children, BAL and endobronchial biopsy should be considered to objectify the presence of airway eosinophilia and other typical pathological features of asthma. ${ }^{13}$ Thus, invasive and tissue-specific diagnostic methods are valuable in certain patient populations and clinical research settings. However, the invasiveness of these diagnostic procedures limits the use of these methods for daily clinical routine in most asthma patients. Even sputum induction, a diagnostic technique in which the patient inhales nebulized saline solution in increasing concentrations to liquefy sputum, is regarded as too invasive, technically complex, and too variable for daily clinical routine. This allocates the procedure to specialized medical centers. ${ }^{14}$ There is a strong correlation between cellular components present in airway fluid obtained by BAL and cells present in airway fluid obtained by sputum induction. ${ }^{15,16}$ Therefore, compared to BAL, sputum induction is the preferred method to diagnose the inflammatory phenotype of asthma classically based on the presence of different types of granulocytes. Recent studies indicate that the performance of this technique increases when combined with the analysis of other cellular components such as exosomes and signaling proteins. ${ }^{17}$

Distinct inflammatory patterns have been established in the sputum of asthmatic adults and asthmatic children based on eosinophil and neutrophil percentages of total nonsquamous cells in the sputum. Currently, four inflammatory phenotypes have been identified based on 


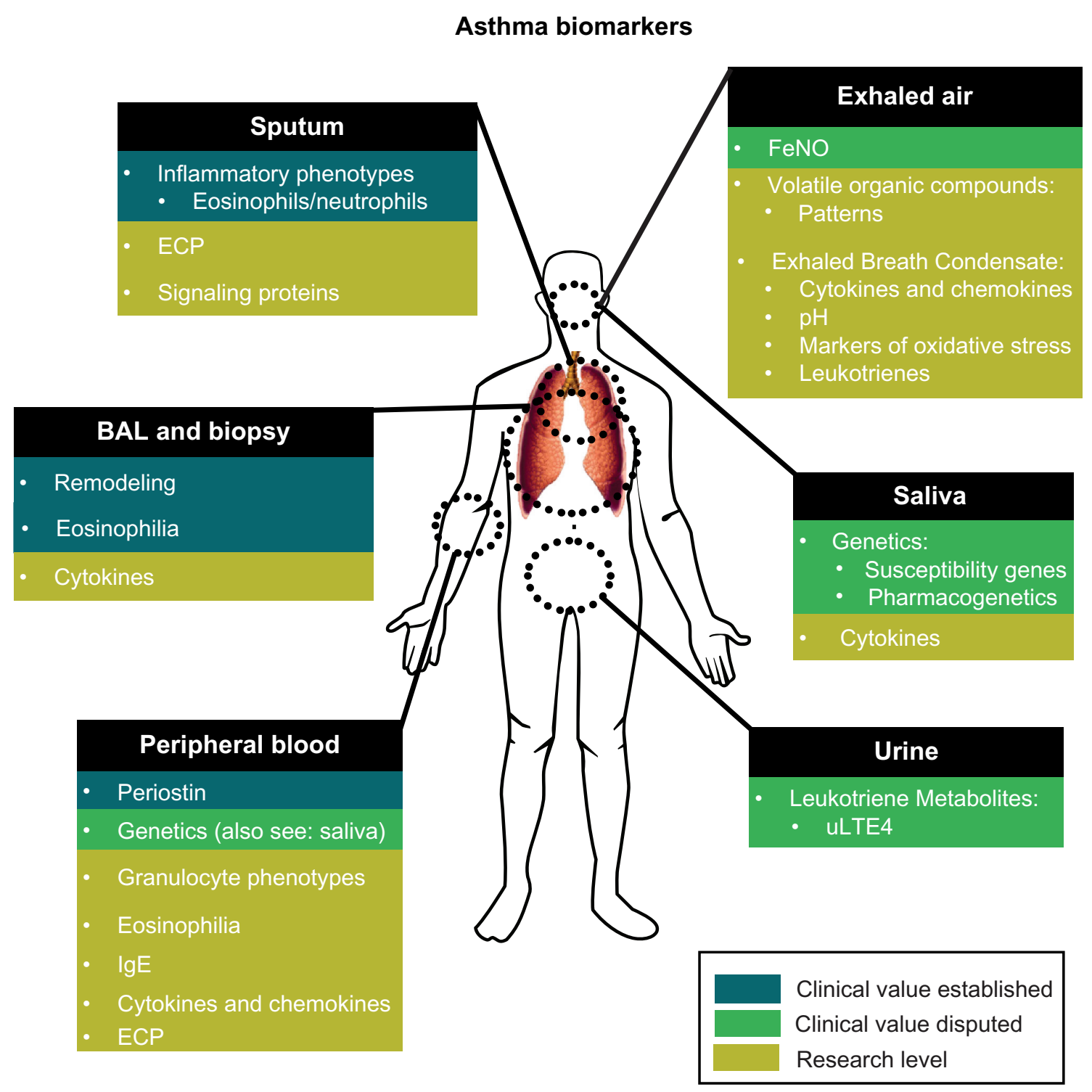

Figure I Asthma biomarkers.

Abbreviations: BAL, bronchoalveolar lavage; ECP, eosinophil cationic protein; FeNO, fraction of exhaled nitric oxide; IgE, immunoglobulin E; uLTE4, urinary leukotriene E4.

analysis of sputum: eosinophilic; neutrophilic; mixed; and paucigranulocytic types (Figure 2 ) ${ }^{18}$ It has been suggested that higher levels of sputum eosinophils are associated with a better response to corticosteroids, ${ }^{19-21}$ but results remain inconsistent. ${ }^{22-24}$ Furthermore, the pattern of inflammatory sputum phenotypes seems to be different for adult patients and pediatric patients, and the reproducibility of sputum induction measurements over time has been a point of scientific debate since the introduction of this technique. $18,25,26$

Other sputum and BAL markers that have been investigated include soluble mediators such as eosinophil cationic protein (ECP), hypoxia inducible factor-1 $\alpha$ (HIF-1 $\alpha)$, and vascular endothelial growth factor (VEGF) ${ }^{27}$ ECP is released during degranulation of eosinophils and can be measured in sputum,
BAL fluid, and in serum. It is considered to be a nonspecific marker for inflammation and therefore lacks the specificity for diagnosing asthma. Meijer et al showed that sputum ECP has no predictive value for clinical response to corticosteroids in asthmatic patients. ${ }^{28}$ Its added value as a diagnostic tool would be in the measurement of the extent of inflammation and severity of asthma; eg, moderate versus severe asthma. ${ }^{29}$ HIF-1 $\alpha$ and VEGF protein levels have shown to be upregulated in lung specimens from allergen-challenged asthma patients obtained by BAL and endobronchial biopsies. ${ }^{30}$

\section{Nitric oxide in exhaled breath}

Almost a decade ago, the first reports emerged of increased levels of nitric oxide in exhaled breath (FeNO) in patients 

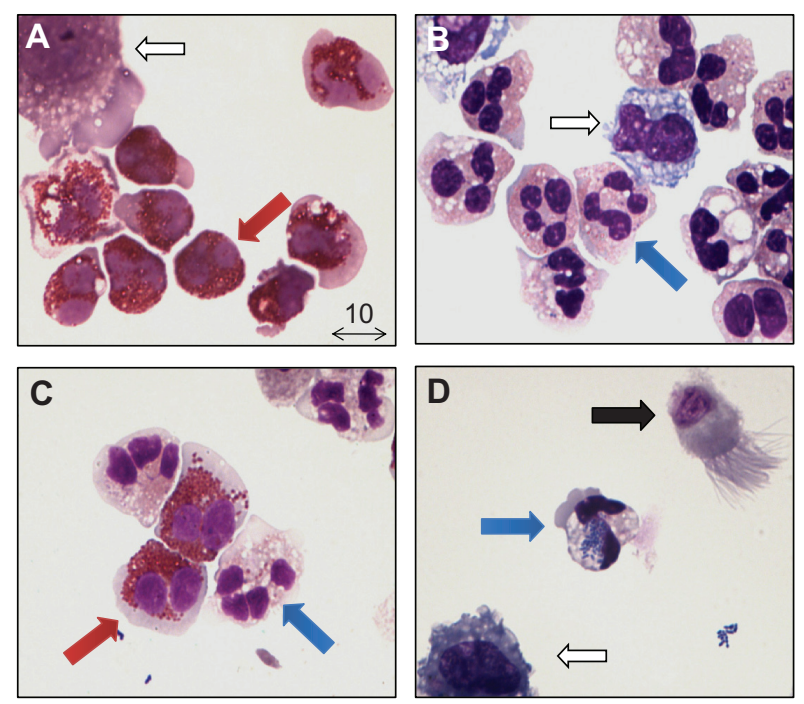

Figure 2 Inflammatory phenotypes of adult asthma patients obtained by sputum induction. (A) Eosinophilic type; marked by the presence of eosinophils $\geq 3 \%$ (red arrow). The hollow arrow indicates an alveolar macrophage. (B) Neutrophilic type; marked by the presence of neutrophils (blue arrow) $\geq 61 \%$. The hollow arrow indicates an alveolar macrophage. (C) Mixed type; marked by the presence of both eosinophils (red arrow) $\geq 3 \%$ and neutrophils (blue arrow) $\geq 61 \%$. (D) Paucigranulocytic type; marked by a lack of eosinophils $(<3 \%)$ and neutrophils $(<61 \%)$. The arrow shows a ciliated pseudostratified columnar airway epithelial cell (black arrow), a neutrophil with phagocytosed bacteria inside (blue arrow) and an alveolar macrophage (hollow arrow). May-Grünwald/Giemsa staining, photograph at 100x magnification, courtesy of Dr JAM van der Linden (UMC Utrecht, The Netherlands).

with asthma. ${ }^{31,32}$ Since then, a high number of studies have assessed the clinical value of exhaled nitric oxide in asthma management. Several FeNO analyzers became commercially available, and international guidelines on FeNO measurement were published. ${ }^{33,34}$

Nitric oxide is produced when the amino acid L-arginine is catalyzed by nitric oxide synthases (NOS) into the amino acid L-citrulline. There are three known isoforms of NOS, but in particular, inducible NOS seems to play a role in the elevated levels of NO in the exhaled breath of asthmatics. The expression of the enzyme is upregulated by a wide range of inflammatory cytokines. It remains unclear which cells are responsible for the increased NO production, but airway epithelial cells and eosinophils are thought to be the most important candidates. ${ }^{35}$ It is thought that inflamed airways will produce increased levels of NO. High FeNO is thought to be a surrogate marker of ongoing eosinophilic airway inflammation, and may reflect uncontrolled asthma and predict asthma exacerbations. ${ }^{36}$

Despite the initial enthusiasm about FeNO as a new and noninvasive marker of airway inflammation, the clinical usefulness of FeNO to measure asthma control is still debated. Studies that have investigated the association between asthma control and FeNO provide inconsistent results (Table 1), and studies assessing the relationship between FeNO and other airway inflammation markers, such as sputum eosinophilia or the presence of eosinophils in bronchial specimens, remain inconclusive. ${ }^{37,38}$ This may be partly caused by a non-overlap in asthma symptoms and airway inflammation. Furthermore, this relationship is complicated due to various other factors that seem to influence FeNO levels, including age, atopy, medication use, therapy adherence, and airway infections. ${ }^{36}$ In addition, tailoring asthma treatment based on FeNO measurements did not decrease asthma exacerbations or lead to better asthma control according to a meta-analysis performed by Petsky et al. ${ }^{39}$ FeNO might, nevertheless, still be a valuable marker in asthma management. Zacharasiewicz et al showed that the combination of increased levels of FeNO and the percentage of sputum eosinophils were significant predictors of exacerbation upon steroid reduction in children with stable asthma. ${ }^{40}$ Studies by Szefler et $\mathrm{al}^{41}$ and Knuffman et $\mathrm{a}^{42}$ showed that pediatric asthma patients with elevated FeNO levels were more likely to respond to corticosteroids compared to montelukast.

Reports on the relationship between FeNO and treatment response remain inconsistent, though there is a suggestion that higher baseline FeNO is associated with a better response to treatment. ${ }^{43}$ Although the clinical value of a single FeNO measurement is limited, combining this measure with other markers of airway inflammation may lead to a more accurate assessment of underlying disease state.

\section{Biomarkers under development Blood}

Peripheral blood is easy to obtain, and the procedure itself is less invasive than sputum induction and bronchoscopy. Since inflamed tissue releases chemoattractants and cytokines, which recruit activated immune cells from the peripheral blood, the dynamic process of immune cells entering and leaving the blood stream can be used as an indirect readout of the state of disease.

Peripheral blood eosinophilia has been described extensively as a potential asthma biomarker. ${ }^{44}$ Blood eosinophilia correlates with bronchial hyperresponsiveness and asthma-related inflammation. ${ }^{45}$ The specificity of using peripheral blood eosinophilia to diagnose asthma is, however, rather low, as allergies, autoimmune disease, and parasitic infections cause blood eosinophilia as well. Therefore, its role as a diagnostic measurement remains limited. The same applies to total and allergen-specific IgE levels in serum. ${ }^{46}$ Several studies have evaluated whether the presence of inflammatory soluble mediators such as chemokines and 


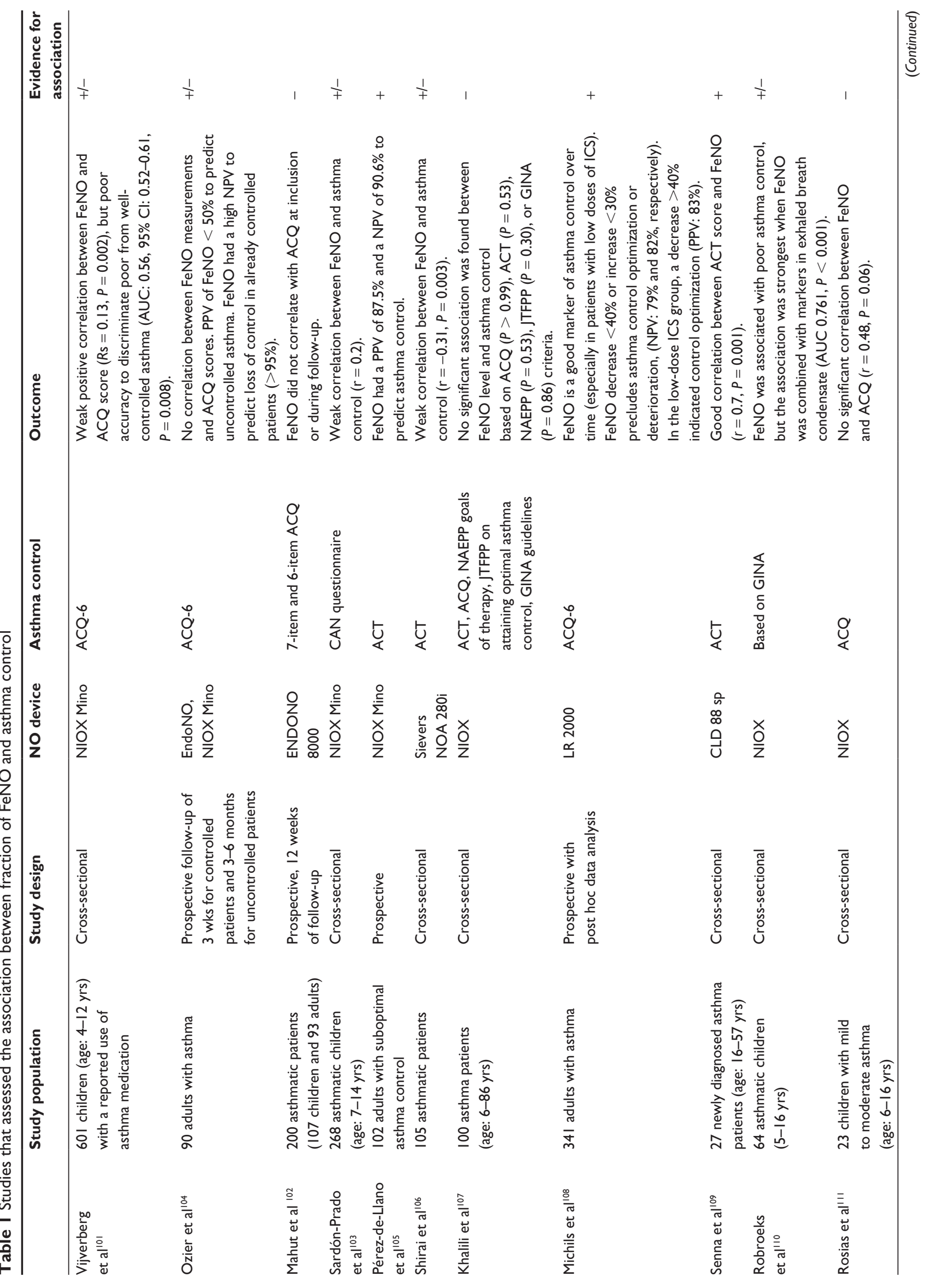




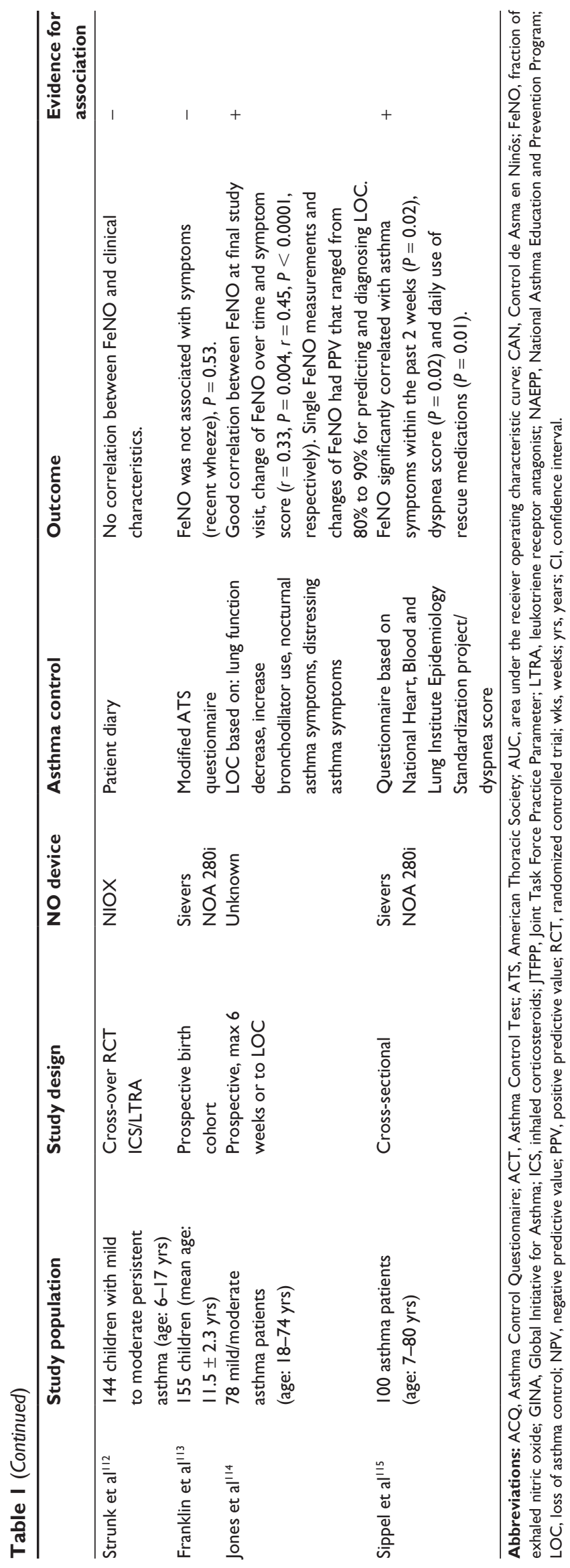

cytokines were applicable as biomarkers for type and extent of asthma phenotypes. ${ }^{47}$ Recent studies utilized multiplex analysis, allowing the parallel analysis of multiple cytokines within one serum/plasma sample. ${ }^{48,49}$ Unfortunately, these studies have led to neither a clinically useful diagnostic tool to identify distinct disease phenotypes, nor to a tool to assess disease severity. A weakness of studies assessing inflammatory chemokine and cytokine profiles lies in the fact that the choice of mediators to be studied determines the (lack of) success of this approach, and that several inflammatory mediators may still be unidentified. Anti-inflammatory mediators (such as receptor antagonists) are often neglected. In addition, little consideration has been given to the complex interaction between inflammatory mediators. ${ }^{50}$

A different approach is to examine shifts in activation profiles of inflammatory cells in peripheral blood and attempt to link these shifts to clinical phenotypes. These inflammatory cells will integrate all pro- and anti-inflammatory signals and change their phenotypes accordingly. Studies on the activation status of peripheral blood cells have provided some insight into the systemic innate immune response in allergic asthma. Many studies have shown that inflammatory cells such as monocytes and granulocytes respond with upregulation of several activation markers in response to inflammatory signals. ${ }^{51-53}$ Many of these markers, such as CD11b/CD18 (Mac-1), CD63, CD66 and CD67, are typically found in granules that fuse with the plasma membrane upon activation of the cells with inflammatory mediators. ${ }^{54}$ Unfortunately, studies ${ }^{55,56}$ that compared the presence of the markers on blood cells and tissue cells obtained from sputum and BAL did not take into account that cells homing to the tissue under homeostatic conditions exhibit the same phenotype. ${ }^{57}$ The process of homing of the cells towards the tissue compartment is already sufficient to activate the cells both in homeostasis as well as in disease. The expression of these markers in the peripheral blood has not led to a clear link between expression profiles of granulocytes and type of asthma.

Elegant work by Johansson et al has shown that eosinophils change their activation status of membranebound integrins rather than overall expression in response to inflammatory signals. ${ }^{58}$ The application of antibodies specifically recognizing activated states of integrins provided solid data that show that blood eosinophils in poorly controlled asthma are characterized by activated integrins. This situation is consistent with the hypothesis that these cells are primed and prepared to leave the peripheral blood for the tissues. We have obtained similar data by the application 
of antibodies recognizing activated Fc $\gamma$ Rs. ${ }^{51,59}$ These data demonstrated that eosinophils become first activated in the peripheral blood and subsequently home for the tissue, leaving behind unprimed cells. ${ }^{60}$ These studies have indicated that changes in the phenotype of inflammatory cells can aid in the diagnosis of the type and extent of severity of allergic asthma. But they also show that the differences are very subtle and not applicable yet in the clinical routine.

Closer to clinical implementation might be the biomarker periostin. Periostin is a recently discovered matricellular protein that is secreted by bronchial epithelial cells under the influence of IL-13. The presence of periostin in serum correlates strongly with sputum eosinophilia. ${ }^{61}$ A study by Corren et al showed that patients with high levels of serum periostin responded better to lebrikizumab (antiIL-13 therapy) compared to patients with low levels of periostin. ${ }^{62}$

\section{Air}

The measurement of volatile organic compounds (VOCs) in exhaled breath is a novel metabolomic approach to study molecular signatures of respiratory disease. Exhaled breath contains a complex mixture of potentially thousands of VOCs. These compounds are produced due to metabolic processes in the airways, and the presence and/or concentrations of the different compounds are likely influenced by the presence of airway inflammation. There exist different methods to assess VOCs; one can assess profiles of VOCs ("breathprints") present in exhaled breath using polymer-based gas sensor arrays ("electronic nose"), ${ }^{63}$ or identify individual molecular components using gas chromatography-mass spectrometry (GC-MS) ${ }^{64}$ Asthma patients can be differentiated from healthy controls based on their breathprints, ${ }^{65}$ as can asthmatic patients from COPD patients. ${ }^{66}$ However, the method was less successful in distinguishing mild asthmatics from severe asthmatics. ${ }^{65}$ Breathprints of COPD patients do correlate with the presence of eosinophils and neutrophils in induced sputum, as well as with levels of ECP and myeloperoxidase in induced sputum, suggesting that the electronic nose might be capable of assessing distinct types of underlying airway inflammation. ${ }^{67}$

Using the other approach, GC-MS, Dallinga et al showed that the measurement of a limited set of VOCs in exhaled air could differentiate asthmatic children from controls with high sensitivity (95\%) and high specificity (89\%). ${ }^{64}$ A study by Ibrahim et al showed that a set of 15 VOCs could discriminate asthmatic patients from controls, and also could classify patients according to inflammatory sputum phenotype and asthma control (based on the Asthma Control Questionnaire). ${ }^{68}$

The assessment of VOC in exhaled breath seems to be a very promising approach, especially when knowledge of clinically relevant VOCs is integrated into a user-friendly handheld device such as an electronic nose. However, validation of clinical relevant VOC patterns in a large population of asthmatic patients is necessary, as well as longitudinal assessment of VOC patterns, the assessment of the influence of asthma treatment, and emergence of international guidelines on VOC measurement. A large Europe-wide study to assess the clinical utility of VOCs in asthma in-depth is currently taking place. ${ }^{69}$

Biomarkers in breath can also be measured in exhaled breath condensate (EBC). When exhaled breath is cooled, a liquid phase can be obtained, which contains condensed water vapor as well as nonvolatile substances. Various markers in EBC have been found to be elevated in asthmatics when compared to healthy individuals, including adenosine concentration, ${ }^{70}$ markers of oxidative stress (ie, hydrogen peroxide), ${ }^{71}$ cytokines and chemokines, ${ }^{72}$ nitric oxide-related products, ${ }^{73}$ isoprostanes, ${ }^{74}$ and leukotrienes. ${ }^{74}$ Furthermore, the $\mathrm{pH}$ of EBC has been reported to be decreased in acute asthmatics and poorly controlled asthmatics. $^{75,76}$

In spite of these results, the measurement of markers in EBC is still in its research phase, and several important methodological problems complicate the clinical utility of EBC..$^{77}$ A standardized methodology for EBC collection is lacking, as are established reference values. Various factors such as the type of condenser equipment used, cooling temperature, condenser tube coating, cleaning procedures, breathing patterns, ambient air pollution, or concentrations of relevant cytokines too low for reliable determination influence the measurement and compromise reproducibility.

\section{Urine: leukotriene metabolites}

Cysteinyl leukotrienes (LTs) $\mathrm{C}_{4}$ and $\mathrm{D}_{4}$ are lipid mediators, which are thought to play a role in asthma pathogenesis. They can be released from various cells, including eosinophils, neutrophils, and mast cells. $\mathrm{LTC}_{4}$ and $\mathrm{LTD}_{4}$ in the plasma are rapidly converted into the less active $\mathrm{LTE}_{4}$ metabolite. A fraction of $\mathrm{LTE}_{4}$ is excreted in urine. The urinary $\mathrm{LTE}_{4}$ $\left(\mathrm{uLTE}_{4}\right)$ concentration is used as a marker of total body LT production. ${ }^{78}$ Studies by Szefler et al and Cai et al showed that asthmatic patients with higher levels of $\mathrm{uLTE}_{4}$ were more likely to respond to leukotriene antagonists (LTRA) 
when compared to asthmatic patients with lower $\mathrm{uLTE}_{4}$ levels. ${ }^{41,79}$

\section{(Pharmaco)genetics}

Twin studies have shown that asthma contains a considerable genetic component. ${ }^{80}$ Genome-wide association studies have identified several loci to be associated with asthma risk, including the $O R M D L 3$ locus, $A D A M 33$, and various cytokines and cytokine receptor genes (IL18R1, IL33, IL2RB, IL10, TGFB1, and IL6R). ${ }^{81-84}$

A recent review by Dijk et al provides a thorough overview of asthma susceptibility genes that have been found by genome-wide association studies. ${ }^{85}$ Nevertheless, effect sizes are small, and the identified genetic variants can only explain a small part of the asthma heritability. This could be due to the heterogeneity in asthma phenotypes and the underestimated influence of environmental-gene interactions. For example, recent work by Ierodiakonou et al showed an interaction between variation in TGFB1 and smoking on asthma severity. ${ }^{86}$ Carrying a G-allele of rs6957 in TGFB1 was associated with higher submucosal eosinophils and basement membrane thickness, but only in current or ex-smoking asthmatics.

A more promising genetic approach for clinical asthma practice might be pharmacogenomics: the association of genomic variations and medication response. Variation in genes coding for proteins involved in the drug metabolism pathway may influence drug concentration and efficacy. Observational studies have found genetic variation to be associated with persistent symptoms as well as with lung function in steroid-treated asthmatics. ${ }^{87-90}$ A study by Hawkins et al found a positive correlation with variations in STIP1, coding for an adaptor protein in the glucocorticoid receptor complex, and baseline lung function and improvement in lung function upon corticosteroid treatment in 382 adults with asthma. ${ }^{89}$ A study by Tantisira et al showed that asthma patients with a variant in the GLCCI1 have less improvement in lung function upon inhaled corticosteroids (ICS) treatment. ${ }^{90}$ GLCCI1 encodes Glucocorticoid Induced Transcript 1, a protein of unknown function. Furthermore, a single-nucleotide polymorphism in the FCER 2 gene, coding for a low-affinity IgE receptor, has been associated with an increased risk of asthma-related hospital visits, uncontrolled asthma, and higher daily steroid dosages..$^{87,88}$ Variation in TBX21 (encoding transcription factor T-bet) has been related to improved airway responsiveness in childhood asthma upon treatment with ICS. ${ }^{91}$ T-bet is thought to be an important regulator of the Th1/Th2 balance. ${ }^{92}$
Pharmacogenomic studies on response to LTRA have found most association with $A L O X 5,{ }^{93,94}$ a 5-lipoxygenase, and $L T C 4 S$, a glutathione S-transferase. ${ }^{95,96}$ However, a step closer to clinical implementation is the assessment of the beta-adrenergic receptor gene $(A D R B 2)$ in order to determine response to $\beta 2$-agonists, for which randomized clinical trial (RCT) data are available. ${ }^{97-99}$ The beta-adrenergic receptor is a G-protein coupled receptor that is expressed in smooth muscle in the airways; activation induces bronchial relaxation. $\beta 2$-agonists are the most frequently prescribed drugs to relieve airway obstruction, and act through the betaadrenergic receptor. Evidence suggests that genetic variations in the gene are associated with an altered treatment response. Recently, a small $\mathrm{RCT}^{97}$ based on prospective testing of genetic variation in the $A D R B 2$ gene (alteration in amino acid at position 16; Arg16Gly) showed encouraging results in 62 children with persistent asthma. Asthmatic children homozygous for the variant genotype were randomized to a long-acting $\beta 2$ agonist (LABA) plus ICS or to LTRA plus ICS. The group treated with ICS and LTRA scored better on asthma symptoms and quality of life, used less rescue medication, and were fewer days absent from school compared to the children treated with LABA plus ICS, ${ }^{97}$ suggesting that asthmatic children homozygous for $A D R B 2$ Arg16Gly substitution (B16 Arg/Arg) benefit more from LTRA compared to LABA as add-on treatment to ICS. Yet there was no difference in lung function improvement.

On the other hand, RCTs performed in adults found no effect. A post hoc pharmacogenetic analysis of two large RCTs in which asthmatic patients were treated with LABA only or LABA combined with ICS found no differences in exacerbations, use of rescue medication, night awakenings, and lung function when patients were stratified according to differences in $A D R B 2$ Arg16Gly genotype. ${ }^{100}$ In a crossover RCT, asthmatic patients with the B16 Arg/Arg (homozygote for the risk allele) or B16 Gly/Gly (homozygote for the wild-type allele) were randomized to LABA plus ICS or placebo plus ICS. There was no difference in lung function improvement between the groups when ICS was added. Remarkably, airway responsiveness in the patients with B16 Gly/Gly did improve significantly when ICS was added to the treatment, while it did not in the B16 Arg/Arg group. ${ }^{98}$ Airway responsiveness was measured as methacholine $\mathrm{PC}_{20}$ doubling dose: the dose of methacholine that provokes a $20 \%$ drop in the volume of exhaled air during the first second of a forced expiratory maneuver.

So far, pharmacogenetic studies have been limited by small sample sizes, heterogeneous populations, and lack 
of replication. However, the emergence of new sequencing technologies and innovative strategies of analyses, as well as the increase in international research consortia, may lead to the identification and replication of clinical relevant associations in the near future. In addition, the development of innovative - though expensive - targeted treatment strategies (such as omalizumab [anti-IgE], mepolizumab [anti-IL5], and lebrikizumab [anti-IL13]) may provide a novel clinical context for pharmacogenetics in order to identify subgroups of asthma patients that will benefit the most from these treatments.

\section{Ease of biomarker detection and current limitations}

Progressive insight into medical biology leads to a layered profile of studying disease mechanisms. Asthma research is shifting from a broad perspective (studying symptom expression, lung function, and response to medication) to a more narrow focus: cellular profiles, protein analysis, and genetic markers, possibly combined with clinical measures. These biological parameters can be measured in different body compartments, and build up to a complexity that has not yet been fully understood. From a biological point of view, there are an almost indefinite number of possible biomarkers that can be measured in the context of asthma. Yet the clinical applicability (eg, clinical added value, specificity, sensitivity, and invasiveness) limits the number of appropriate clinical usable biomarkers. Noninvasive, reliable, and easily interpreted biomarkers would ideally be standard in daily clinical routine, but are currently unavailable.

\section{Conclusion and future directions}

Single biomarker approaches to phenotype asthma are increasingly regarded to be inaccurate and outdated. In diagnosing the presence of eosinophilic inflammation for example, FeNO is a very sensitive biomarker, but not very specific. Intuitively, combining FeNO with markers of eosinophilic inflammation (such as the percentage of eosinophils in peripheral blood or eosinophil receptor expression) or other biomarkers would increase specificity. To test this hypothesis, studies combining multiple known biomarkers should be performed. Currently, research consortia like U-BIOPRED (Unbiased Biomarkers in Prediction of Respiratory Disease Outcomes, http://www. ubiopred.european-lung-foundation.org/) and SARP (Severe Asthma Research Program, http://www.severeasthma. org) aim to integrate the process of data collection and multidimensional approaches to phenotype asthma.
Single biomarker approaches remain important in the process of biomarker discovery, as newly identified biomarkers can be integrated in a multidimensional approach to strengthen the diagnostic ability of a clinically applicable algorithm to phenotype asthma. Only then will personalized asthma treatment be in reach.

\section{Disclosure}

Susanne JH Vijverberg has been paid by an unrestricted grant from GlaxoSmithKline (GSK). Bart Hilvering has no financial relationship with a commercial entity that has an interest in the subject of this manuscript. Jan AM Raaijmakers is a part-time professor at the Utrecht University, Vice-President External Scientific Collaborations for GSK in Europe, and holds stock in GSK. Anke-Hilse Maitland-van der Zee received an unrestricted grant from GSK. Furthermore, the department of Pharmacoepidemiology and Clinical Pharmacology, Utrecht Institute for Pharmaceutical Sciences, which employs authors Susanne JH Vijverberg, Jan AM Raaijmakers, and Anke-Hilse Maitland-van der Zee, has received unrestricted research funding from the Netherlands Organisation for Health Research and Development, the Dutch Health Care Insurance Board, the Royal Dutch Pharmacists Association, the private public-funded Top Institute Pharma, including co-funding from universities, government, the EU Innovative Medicines Initiative, EU 7th Framework Program, the Dutch Medicines Evaluation Board, the Dutch Ministry of Health, and industry (including GSK, Pfizer, and others). Jan-Willem Lammers and Leo Koenderman are full professors in the Department of Respiratory Medicine at the University Medical Centre Utrecht. Both collaborated in a TI-Pharma-funded project. TI-Pharma is a public private partnership between the Universities of Utrecht, Groningen, Maastricht, the Dutch government, GSK, Nycomed, and Danone.

\section{References}

1. Global strategy for asthma management and prevention. Global Initiative for Asthma (GINA); 2012. Available from: http://www.ginasthma.org/ documents/4. Accessed June 20, 2013.

2. Masoli M, Fabian D, Holt S, Beasley R, Global Initiative for Asthma (GINA) Program. The global burden of asthma: executive summary of the GINA dissemination committee report. Allergy. 2004;59(5):469-478.

3. Busse WW, Lemanske RF. Asthma. N Engl J Med. 2001;344(5): 350-362.

4. Hwang SS, Kim YU, Lee S, et al. Transcription factor YY1 is essential for regulation of the Th2 cytokine locus and for Th2 cell differentiation. Proc Natl Acad Sci US A. 2013;110(1):276-281.

5. Barnes PJ. The cytokine network in asthma and chronic obstructive pulmonary disease. J Clin Invest. 2008;118(11):3546-3556.

6. Holtzman MJ. Asthma as a chronic disease of the innate and adaptive immune systems responding to viruses and allergens. J Clin Invest. 2012;122(8):2741-2748. 
7. Mauad T, Bel EH, Sterk PJ. Asthma therapy and airway remodeling. $J$ Allergy Clin Immunol. 2007;120(5):997-1009.

8. Baena-Cagnani CA, Rossi GA, Canonica GW. Airway remodeling in children: When does it start? Curr Opin Allergy Clin Immunol. 2007;7(2):196-200.

9. Connett GJ. Bronchoalveolar lavage. Paediatr Respir Rev. 2000;1(1): 52-56.

10. Haldar P, Pavord ID, Shaw DE, et al. Cluster analysis and clinical asthma phenotypes. Am J Respir Crit Care Med. 2008;178(3): 218-224.

11. Bossley CJ, Fleming L, Gupta A, et al. Pediatric severe asthma is characterized by eosinophilia and remodeling without TH2 cytokines. J Allergy Clin Immunol. 2012;129(4):974-982. e13.

12. Brightling CE, Symon FA, Birring SS, Bradding P, Pavord ID, Wardlaw AJ. TH2 cytokine expression in bronchoalveolar lavage fluid T lymphocytes and bronchial submucosa is a feature of asthma and eosinophilic bronchitis. J Allergy Clin Immunol. 2002;110(6): 899-905.

13. Payne D, McKenzie SA, Stacey S, Misra D, Haxby E, Bush A. Safety and ethics of bronchoscopy and endobronchial biopsy in difficult asthma. Arch Dis Child. 2001;84(5):423-426.

14. Petsky HL, Kynaston JA, Turner C, et al. Tailored interventions based on sputum eosinophils versus clinical symptoms for asthma in children and adults. Cochrane Database Syst Rev. 2007;(2): CD005603.

15. Fahy JV. Eosinophilic and neutrophilic inflammation in asthma: insights from clinical studies. Proc Am Thorac Soc. 2009;6(3):256-259.

16. Macedo P, Hew M, Torrego A, et al. Inflammatory biomarkers in airways of patients with severe asthma compared with non-severe asthma. Clin Exp Allergy. 2009;39(11):1668-1676.

17. Hou C, Zhao H, Li W, et al. Increased heat shock protein 70 levels in induced sputum and plasma correlate with severity of asthma patients. Cell Stress Chaperones. 2011;16(6):663-671.

18. Simpson JL, Scott R, Boyle MJ, Gibson PG. Inflammatory subtypes in asthma: Assessment and identification using induced sputum. Respirology. 2006;11(1):54-61.

19. Pavord ID, Brightling CE, Woltmann G, Wardlaw AJ. Non-eosinophilic corticosteroid unresponsive asthma. Lancet. 1999;353(9171): 2213-2214.

20. Bacci E, Cianchetti S, Bartoli M, et al. Low sputum eosinophils predict the lack of response to beclomethasone in symptomatic asthmatic patients. Chest. 2006;129(3):565-572.

21. Green RH, Brightling CE, McKenna S, et al. Asthma exacerbations and sputum eosinophil counts: A randomised controlled trial. Lancet. 2002;360(9347):1715-1721.

22. Martin RJ, Szefler SJ, King TS, et al. The Predicting Response to Inhaled Corticosteroid Efficacy (PRICE) trial. JAllergy Clin Immunol. 2007;119(1):73-80.

23. Lex C, Jenkins G, Wilson NM, et al. Does sputum eosinophilia predict the response to systemic corticosteroids in children with difficult asthma? Pediatr Pulmonol. 2007;42(3):298-303.

24. Wenzel SE. Eosinophils in asthma - closing the loop or opening the door? N Engl J Med. 2009;360(10):1026-1028.

25. Wang F, He XY, Baines KJ, et al. Different inflammatory phenotypes in adults and children with acute asthma. Eur Respir J. 2011;38(3): $567-574$.

26. Fleming L, Wilson N, Regamey N, Bush A. Are inflammatory phenotypes in children with severe asthma stable? Eur Respir J. 2007;30(Suppl 51):483S.

27. Fahy JV, Liu J, Wong H, Boushey HA. Analysis of cellular and biochemical constituents of induced sputum after allergen challenge: a method for studying allergic airway inflammation. J Allergy Clin Immunol. 1994;93(6):1031-1039.

28. Meijer RJ, Postma DS, Kauffman HF, Arends LR, Koëter GH, Kerstjens HA. Accuracy of eosinophils and eosinophil cationic protein to predict steroid improvement in asthma. Clin Exp Allergy. 2002;32(7):1096-1103.
29. Koh GC, Shek LP, Goh DY, Van Bever H, Koh DS. Eosinophil cationic protein: is it useful in asthma? A systematic review. Respir Med. 2007:101(4):696-705.

30. Huerta-Yepez S, Baay-Guzman GJ, Bebenek IG, et al. Hypoxia inducible factor promotes murine allergic airway inflammation and is increased in asthma and rhinitis. Allergy. 2011;66(7):909-918.

31. Kharitonov SA, Yates D, Robbins RA, Logan-Sinclair R, Shinebourne EA, Barnes PJ. Increased nitric oxide in exhaled air of asthmatic patients. Lancet. 1994;343(8890):133-135.

32. Alving K, Weitzberg E, Lundberg JM. Increased amount of nitric oxide in exhaled air of asthmatics. Eur Respir J. 1993;6(9):1368-1370.

33. Dweik RA, Boggs PB, Erzurum SC, et al. An official ATS clinical practice guideline: interpretation of exhaled nitric oxide levels (FeNO) for clinical applications. Am J Respir Crit Care Med. 2011;184(5): $602-615$.

34. Kharitonov S, Alving K, Barnes PJ. Exhaled and nasal nitric oxide measurements: recommendations. The European Respiratory Society Task Force. Eur Respir J. 1997;10(7):1683-1693.

35. Yates DH. Role of exhaled nitric oxide in asthma. Immunol Cell Biol. 2001;79(2):178-190

36. Pijnenburg MW, Jongste JC. Exhaled nitric oxide in childhood asthma: a review. Clin Exp Allergy. 2008;38(2):246-259.

37. Payne DN, Adcock IM, Wilson NM, Oates T, Scallan M, Bush A. Relationship between exhaled nitric oxide and mucosal eosinophilic inflammation in children with difficult asthma, after treatment with oral prednisolone. Am J Respir Crit Care Med. 2001;164(8 Pt 1): 1376-1381.

38. Lemière $\mathrm{C}$, Ernst $\mathrm{P}$, Olivenstein $\mathrm{R}$, et al. Airway inflammation assessed by invasive and noninvasive means in severe asthma: eosinophilic and noneosinophilic phenotypes. J Allergy Clin Immunol. 2006;118(5): 1033-1039.

39. Petsky HL, Cates CJ, Li A, Kynaston JA, Turner C, Chang AB. Tailored interventions based on exhaled nitric oxide versus clinical symptoms for asthma in children and adults. Cochrane Database Syst Rev. 2009;(4):CD006340.

40. Zacharasiewicz A, Wilson N, Lex C, et al. Clinical use of noninvasive measurements of airway inflammation in steroid reduction in children. Am J Respir Crit Care Med. 2005;171(10):1077-1082.

41. Szefler SJ, Phillips BR, Martinez FD, et al. Characterization of withinsubject responses to fluticasone and montelukast in childhood asthma. J Allergy Clin Immunol. 2005;115(2):233-242.

42. Knuffman JE, Sorkness CA, Lemanske RF Jr, et al. Phenotypic predictors of long-term response to inhaled corticosteroid and leukotriene modifier therapies in pediatric asthma. J Allergy Clin Immunol. 2009;123(2):411-416.

43. Vijverberg SJ, Koenderman L, Koster ES, van der Ent CK, Raaijmakers JA, Maitland-van der Zee AH. Biomarkers of therapy responsiveness in asthma: Pitfalls and promises. Clin Exp Allergy. 2011;41(5):615-629.

44. Massanari M, Holgate ST, Busse WW, Jimenez P, Kianifard F, Zeldin R. Effect of omalizumab on peripheral blood eosinophilia in allergic asthma. Respir Med. 2010;104(2):188-196.

45. Jansen DF, Rijcken B, Schouten JP, et al. The relationship of skin test positivity, high serum total IgE levels, and peripheral blood eosinophilia to symptomatic and asymptomatic airway hyperresponsiveness. Am J Respir Crit Care Med. 1999;159(3):924-931.

46. Platts-Mills TA. The role of immunoglobulin E in allergy and asthma. Am J Respir Crit Care Med. 2001;164(8 Pt 2):S1-S5.

47. Bhakta NR, Woodruff PG. Human asthma phenotypes: from the clinic, to cytokines, and back again. Immunol Rev. 2011;242(1):220-232.

48. Kato M, Yamada Y, Maruyama K, Hayashi Y. Serum eosinophil cationic protein and 27 Cytokines/Chemokines in acute exacerbation of childhood asthma. Int Arch Allergy Immunol. 2010;152 Suppl 1:62-66.

49. Patil SP, Wisnivesky JP, Busse PJ, Halm EA, Li XM. Detection of immunological biomarkers correlated with asthma control and quality of life measurements in sera from chronic asthmatic patients. Ann Allergy Asthma Immunol. 2011;106(3):205-213. 
50. Langereis JD, Schweizer RC, Lammers JW, Koenderman L, Ulfman LH. A unique protein profile of peripheral neutrophils from COPD patients does not reflect cytokine-induced protein profiles of neutrophils in vitro. BMC Pulm Med. 2011;11:44.

51. Kanters D, ten Hove W, Luijk B, et al. Expression of activated Fc $\gamma$ RII discriminates between multiple granulocyte-priming phenotypes in peripheral blood of allergic asthmatic subjects. J Allergy Clin Immunol. 2007;120(5):1073-1081.

52. Johansson MW, Kelly EA, Busse WW, Jarjour NN, Mosher DF. Up-regulation and activation of eosinophil integrins in blood and airway after segmental lung antigen challenge. J Immunol. 2008;180(11):7622-7635.

53. Pillay J, Kamp VM, van Hoffen E, et al. A subset of neutrophils in human systemic inflammation inhibits T cell responses through Mac-1. J Clin Invest. 2012;122(1):327-336.

54. Faurschou M, Borregaard N. Neutrophil granules and secretory vesicles in inflammation. Microbes Infect. 2003;5(14):1317-1327.

55. Mengelers HJ, Maikoe T, Brinkman L, Hooibrink B, Lammers JW, Koenderman L. Immunophenotyping of eosinophils recovered from blood and BAL of allergic asthmatics. Am J Respir Crit Care Med. 1994;149(2):345-351.

56. Kelly EA, Koziol-White CJ, Clay KJ, et al. Potential contribution of IL-7 to allergen-induced eosinophilic airway inflammation in asthma. J Immunol. 2009;182(3):1404-1410.

57. Fortunati E, Kazemier KM, Grutters JC, Koenderman L, Van den Bosch VJ. Human neutrophils switch to an activated phenotype after homing to the lung irrespective of inflammatory disease. Clin Exp Immunol. 2009;155(3):559-566.

58. Johansson MW, Barthel SR, Swenson CA, et al. Eosinophil $\beta 1$ integrin activation state correlates with asthma activity in a blind study of inhaled corticosteroid withdrawal. JAllergy Clin Immunol. 2006;117(6): $1502-1504$.

59. Luijk B, Lindemans CA, Kanters D, et al. Gradual increase in priming of human eosinophils during extravasation from peripheral blood to the airways in response to allergen challenge. J Allergy Clin Immunol. 2005;115(5):997-1003.

60. Koenderman L, van der Linden J, Ulfman L, Coffer P. Eosinophils. In: Rogers DF, Donnelly LE, editors. Human Airway Inflammation. Vol 56. Totowa (NJ): Humana Press; 2001:217-226.

61. Jia G, Erickson RW, Choy DF, et al. Periostin is a systemic biomarker of eosinophilic airway inflammation in asthmatic patients. J Allergy Clin Immunol. 2012;130(3):647-654.e10.

62. Corren J, Lemanske RF, Hanania NA, et al. Lebrikizumab treatment in adults with asthma. $N$ Engl J Med. 2011;365(12): 1088-1098.

63. Wilson AD, Baietto M. Advances in electronic-nose technologies developed for biomedical applications. Sensors. 2011;11(1): 1105-1176.

64. Dallinga JW, Robroeks CM, van Berkel JJ, et al. Volatile organic compounds in exhaled breath as a diagnostic tool for asthma in children. Clin Exp Allergy. 2010;40(1):68-76.

65. Dragonieri S, Schot R, Mertens BJ, et al. An electronic nose in the discrimination of patients with asthma and controls. J Allergy Clin Immunol. 2007;120(4):856-862.

66. Fens N, Zwinderman AH, van der Schee MP, et al. Exhaled breath profiling enables discrimination of chronic obstructive pulmonary disease and asthma. Am J Respir Crit Care Med. 2009;180(11): 1076-1082.

67. Fens N, de Nijs SB, Peters S, et al. Exhaled air molecular profiling in relation to inflammatory subtype and activity in COPD. Eur Respir J. 2011;38(6):1301-1309.

68. Ibrahim B, Basanta M, Cadden P, et al. Non-invasive phenotyping using exhaled volatile organic compounds in asthma. Thorax. 2011;66(9):804-809.

69. U-BIOPRED [webpage on the Internet]. European Lung Foundation. Available from: http://www.ubiopred.european-lung-foundation.org. Accessed May 2, 2013.
70. Lázár Z, Cervenak L, Orosz M, et al. Adenosine triphosphate concentration of exhaled breath condensate in asthma. Chest. 2010;138(3): 536-542.

71. Loukides S, Bouros D, Papatheodorou G, Panagou P, Siafakas NM. The relationships among hydrogen peroxide in expired breath condensate, airway inflammation, and asthma severity. Chest. 2002;121(2): $338-346$.

72. Robroeks CM, Rijkers GT, Jöbsis Q, et al. Increased cytokines, chemokines and soluble adhesion molecules in exhaled breath condensate of asthmatic children. Clin Exp Allergy. 2010;40(1):77-84.

73. Donnelly LE. Exhaled breath condensate: Nitric oxide-related compounds. In: Horvath I, de Jongste JC, editors. European Respiratory Monograph (Exhaled Biomakers). 2010:207-216.

74. Montuschi P. Exhaled breath condensate: 8-isoprostane and eicosanoids. In: Horvath I, de Jongste JC, eds. European respiratory monograph: exhaled biomarkers, Volume 49. Sheffield, UK: European Respiratory Society Journals Ltd. 2010;196-206.

75. Tseliou E, Bessa V, Hillas G, et al. Exhaled nitric oxide and exhaled breath condensate $\mathrm{pH}$ in severe refractory asthma. Chest. 2010;138(1): 107-113.

76. Bikov A, Antus B, Losonczy G, Horvath I. Exhaled breath condensate pH. In: Horvath I, de Jongste JC, editors. European Respiratory Monograph (Exhaled Biomarkers). 2010:173-182.

77. Horvath I, Hunt J, Barnes PJ, et al. Exhaled breath condensate: Methodological recommendations and unresolved questions. Eur Respir J. 2005;26(3):523-548.

78. Rabinovitch N. Urinary leukotriene E4 as a biomarker of exposure, susceptibility and risk in asthma. Immunol Allergy Clin North Am. 2012;32(3):433-445.

79. Cai C, Yang J, Hu S, Zhou M, Guo W. Relationship between urinary cysteinyl leukotriene E4 levels and clinical response to antileukotriene treatment in patients with asthma. Lung. 2007;185(2):105-112.

80. Los H, Postmus PE, Boomsma DI. Asthma genetics and intermediate phenotypes: A review from twin studies. Twin Res. 2001;4(2):81-93.

81. Ferreira MA, Matheson MC, Duffy DL, et al. Identification of IL6R and chromosome 11q13.5 as risk loci for asthma. Lancet. 2011;378(9795): 1006-1014.

82. Moffatt MF, Gut IG, Demenais F, et al. A large-scale, consortium-based genomewide association study of asthma. NEngl J Med. 2010;363(13): 1211-1221.

83. Himes BE, Hunninghake GM, Baurley JW, et al. Genome-wide association analysis identifies PDE4D as an asthma-susceptibility gene. Am J Hum Genet. 2009;84(5):581-593.

84. Hobbs K, Negri J, Klinnert M, Rosenwasser L, Borish L. Interleukin-10 and transforming growth factor-beta promoter polymorphisms in allergies and asthma. Am J Respir Crit Care Med. 1998;158(6): 1958-1962.

85. Dijk FN, de Jongste JC, Postma DS, Koppelman GH. Genetics of onset of asthma. Curr Opin Allergy Clin Immunol. 2013;13(2):193-202.

86. Ierodiakonou D, Postma DS, Koppelman GH, et al. TGF- $\beta 1$ polymorphisms and asthma severity, airway inflammation, and remodeling. J Allergy Clin Immunol. 2013;131(2):582-585.

87. Tantisira KG, Silverman ES, Mariani TJ, et al. FCER2: A pharmacogenetic basis for severe exacerbations in children with asthma. J Allergy Clin Immunol. 2007;120(6):1285-1291.

88. Koster ES, Maitland-van der Zee AH, Tavendale R, et al. FCER2 T2206C variant associated with chronic symptoms and exacerbations in steroid-treated asthmatic children. Allergy. 2011;66(12):1546-1552.

89. Hawkins GA, Lazarus R, Smith RS, et al. The glucocorticoid receptor heterocomplex gene STIP1 is associated with improved lung function in asthmatic subjects treated with inhaled corticosteroids. JAllergy Clin Immunol. 2009;123(6):1376-1383. e7.

90. Tantisira KG, Lasky-Su J, Harada M, et al. Genomewide association between GLCCI1 and response to glucocorticoid therapy in asthma. N Engl J Med. 2011;365(13):1173-1183.

91. Tantisira KG, Hwang ES, Raby BA, et al. TBX21: A functional variant predicts improvement in asthma with the use of inhaled corticosteroids. Proc Natl Acad Sci U S A. 2004;101(52):18099-18104. 
92. Li JR, Li JG, Deng GH, et al. A common promoter variant of TBX21 is associated with allele specific binding to yin-yang 1 and reduced gene expression. Scand J Immunol. 2011;73(5):449-458.

93. Telleria JJ, Blanco-Quiros A, Varillas D, et al. ALOX5 promoter genotype and response to montelukast in moderate persistent asthma. Respir Med. 2008;102(6):857-861.

94. Drazen JM, Yandava CN, Dube L, et al. Pharmacogenetic association between ALOX5 promoter genotype and the response to anti-asthma treatment. Nat Genet. 1999;22(2):168-170.

95. Sampson AP, Siddiqui S, Buchanan D, et al. Variant LTC4 synthase allele modifies cysteinyl leukotriene synthesis in eosinophils and predicts clinical response to zafirlukast. Thorax. 2000;55(Suppl 2): S28-S31.

96. Kang MJ, Kwon JW, Kim BJ, et al. Polymorphisms of the PTGDR and LTC4S influence responsiveness to leukotriene receptor antagonists in Korean children with asthma. J Hum Genet. 2011;56(4):284-289.

97. Lipworth BJ, Basu K, Donald HP, et al. Tailored second-line therapy in asthmatic children with the $\arg (16)$ genotype. Clin Sci (Lond). 2013;124(8):521-528.

98. Wechsler ME, Kunselman SJ, Chinchilli VM, et al. Effect of [beta]2adrenergic receptor polymorphism on response to longacting [beta]2 agonist in asthma (LARGE trial): A genotype-stratified, randomised, placebo-controlled, crossover trial. Lancet. 2009;374(9703): 1754-1764.

99. Bleecker ER, Nelson HS, Kraft M, et al. $\beta 2$-receptor polymorphisms in patients receiving salmeterol with or without fluticasone propionate. Am J Respir Crit Care Med. 2010;181(7):676-687.

100. Bleecker ER, Postma DS, Lawrance RM, Meyers DA, Ambrose HJ, Goldman M. Effect of ADRB2 polymorphisms on response to longacting $\beta 2$-agonist therapy: A pharmacogenetic analysis of two randomised studies. Lancet. 2007;370(9605):2118-2125.

101. Vijverberg SJH, Koster ES, Koenderman L, et al. Exhaled NO is a poor marker of asthma control in children with a reported use of asthma medication: A pharmacy-based study. Pediatr Allergy Immunol. 2012;23(6):529-536.

102. Mahut B, Trinquart L, Le Bourgeois M, et al. Multicentre trial evaluating alveolar NO fraction as a marker of asthma control and severity. Allergy. 2010;65(5):636-644.

103. Sardón-Prado O, Korta-Murua J, Valverde-Molina J, et al. Association among lung function, exhaled nitric oxide, and the CAN questionnaire to assess asthma control in children. Pediatr Pulmonol. 2010;45(5): 434-439.
104. Ozier A, Girodet P, Bara I, Tunon de Lara J, Marthan R, Berger P. Control maintenance can be predicted by exhaled NO monitoring in asthmatic patients. Respir Med. 2011;105(7):989-996.

105. Perez-de-Llano LA, Carballada F, Castro Anon O, et al. Exhaled nitric oxide predicts control in patients with difficult-to-treat asthma. Eur Resp J. 2010;35(6):1221-1227.

106. Shirai T, Furuhashi K, Suda T, Chida K. Relationship of the asthma control test with pulmonary function and exhaled nitric oxide. Ann Allergy Asthma Immunol. 2008;101(6):608-613.

107. Khalili B, Boggs PB, Shi R, Bahna SL. Discrepancy between clinical asthma control assessment tools and fractional exhaled nitric oxide. Ann Allergy Asthma Immunol. 2008;101(2):124-129.

108. Michils A, Baldassarre S, Van Muylem A. Exhaled nitric oxide and asthma control: a longitudinal study in unselected patients. Eur Respir J. 2008;31(3):539-546.

109. Senna G, Passalacqua G, Schiappoli M, Lombardi C, Wilcock L. Correlation among FEV1, nitric oxide and asthma control test in newly diagnosed asthma. Allergy. 2007;62(2):207-208.

110. Robroeks CM, van de Kant KD, Jöbsis Q, et al. Exhaled nitric oxide and biomarkers in exhaled breath condensate indicate the presence, severity and control of childhood asthma. Clin Exp Allergy. 2007;37(9):1303-1311.

111. Rosias PP, Dompeling E, Dentener MA, et al. Childhood asthma: exhaled markers of airway inflammation, asthma control score, and lung function tests. Pediatr Pulmonol. 2004;38(2):107-114.

112. Strunk RC, Szefler SJ, Phillips BR, et al. Relationship of exhaled nitric oxide to clinical and inflammatory markers of persistent asthma in children. J Allergy Clin Immunol. 2003;112(5):883-892.

113. Franklin PJ, Turner SW, Le Souëf PN, Stick SM. Exhaled nitric oxide and asthma: Complex interactions between atopy, airway responsiveness, and symptoms in a community population of children. Thorax. 2003;58(12):1048-1052.

114. Jones SL, Kittelson J, Cowan JO, et al. The predictive value of exhaled nitric oxide measurements in assessing changes in asthma control. Am J Respir Crit Care Med. 2001;164(5):738-743.

115. Sippel JM, Holden WE, Tilles SA, et al. Exhaled nitric oxide levels correlate with measures of disease control in asthma. J Allergy Clin Immunol. 2000;106(4):645-650.
Biologics: Targets \& Therapy

\section{Publish your work in this journal}

Biologics: Targets \& Therapy is an international, peer-reviewed journal focusing on the patho-physiological rationale for and clinical application of Biologic agents in the management of autoimmune diseases, cancers or other pathologies where a molecular target can be identified. This journal is indexed on PubMed Central, CAS, EMBase, Scopus

\section{Dovepress}

and the Elsevier Bibliographic databases. The manuscript management system is completely online and includes a very quick and fair peerreview system, which is all easy to use. Visit http://www.dovepress com/testimonials.php to read real quotes from published authors. 